\title{
Traditional Living Habits of the Taz Tundra Population: A Paleoparasitological Study
}

\author{
Sergey Mikhailovich Slepchenko, ${ }^{1,2,3, *}$, Sergey Nikolaevich Ivanov', Bagashev Anatoly Nikolaevich', \\ Tsybankov Alexander Alekseevich², Slavinsky Vyacheslav Sergeyevich ${ }^{2}$ \\ IInstitute for Problems of the Development of the North, Siberian Branch of the Russian Academy of Sciences, Tyumen 625026 Russian Federation; \\ 2Institute of Archaeology and Ethnography Siberian Branch of the Russian Academy of Sciences, Novosibirsk 630090, Russian Federation; \\ ${ }^{3}$ Scientific Center of the Russian Academy of Sciences, Tyumen, Russian Federation
}

\begin{abstract}
An excavation of the Vesakoyakha II-IV and Nyamboyto I burial grounds was conducted during the 2014 field season, and soil samples from intact burials dating from the 19th and 20th centuries, respectively, were analyzed to determine interactions between parasites and host/vectors. Considering the discovery of Diphyllobothrium sp. and Taenia sp. eggs in soil samples from the pelvic region, diphyllobothriasis was the most frequent helminthic infection among the Taz Nenets. The Nyamboyto Nenets mainly consumed uncooked fish, while the Vesakoyakha Nenets had a bigger variety in food choices, including reindeer meat. Nenets children were given raw fish from early childhood. The paleoparasitological results corroborate rare ethnographic records about the consumption of uncooked reindeer cerebrum which led to beef tapeworm helminthiases. This is the first parasitological report of helminthic diseases among the Taz Nenets, and, as such, it provides insight into their subsistence activities and food patterns and broadens our understanding of their health condition.
\end{abstract}

Key words: Taenia saginata, Diphyllobothrium latum, Western Siberia, paleoparasitology, health status, dietary habit, Nenets, food pattern, subsistence activity

\section{INTRODUCTION}

Paleoparasitology is the study of parasites found in ancient remains. Different archeological and paleontological objects are analyzed, such as soil samples, coprolites, or hair [1]. Paleoparasitology reveals the existence of parasites in the past and helps to trace the relationship between parasites and final hosts. Thus, it sheds light on the origin and evolution of parasitic infections. Moreover, paleoparasitology contributes to a better understanding of paleodiet, paleopathology, sanitary conditions, life style and migration paths of ancient human populations [1].

Paleoparasitological studies have not yet been performed on archeological sites left by indigenous Arctic ethnic groups Nenets in West Siberia. Here, for the first time, we introduce paleoparasitological results from the burial ground of the Taz

- Received 23 February 2016, revised 16 May 2016, accepted 8 June 2016.

*Corresponding author (s_slepchenko@list.ru)

* This article is dedicated to the memory of our wonderful colleague, D. Sci. Adauto Araújo, who passed away, but he continues to live in our hearts.

(C) 2016, Korean Society for Parasitology and Tropical Medicine

This is an Open Access article distributed under the terms of the Creative Commons Attribution Non-Commercial License (http://creativecommons.org/licenses/by-nc/4.0) which permits unrestricted non-commercial use, distribution, and reproduction in any

medium, provided the original work is properly cited.
Nenets people.

Descendants of those interred in the Vesakoyakha III-IV and Nyamboyto I burial grounds ethnically belong to the Nenets, indigenous people in northern arctic Russia, more specifically the lower reaches of the Taz River and its tributaries [2]. These Siberian Tundra Nenets, together with the European and Forest Nenets, form a large single ethnic family in Northern Eurasia from the Pechora River to the mouth of Yenisei River (Fig. 1).

Archeological data suggest that Samoyedic languages originated in the Volgo-Kama region in the Neolithic period. Later, ancient Samoyedic people moved farther eastward. The ancestors of Nenets, native Samoyedic speakers, began to leave the Sayano-Altay highlands and moved to the Near Arctic and Arctic Circle in the 3rd century AD. The migration process lasted almost a thousand years. In the 17th century, the Nenets entered the Taz River Basin and moved farther to the northeast, displacing and assimilating the Enets people, another Samoyedic people [3].

Along with the North-Samoyedic group, the Taz Nenets taxonomically belong to the Yenisei anthropological group of the North Asian race [4]. The Nenets' language, together with the languages of both Enets and Nganasan, is related to the northern branch of the Samoyedic language group, which, together 


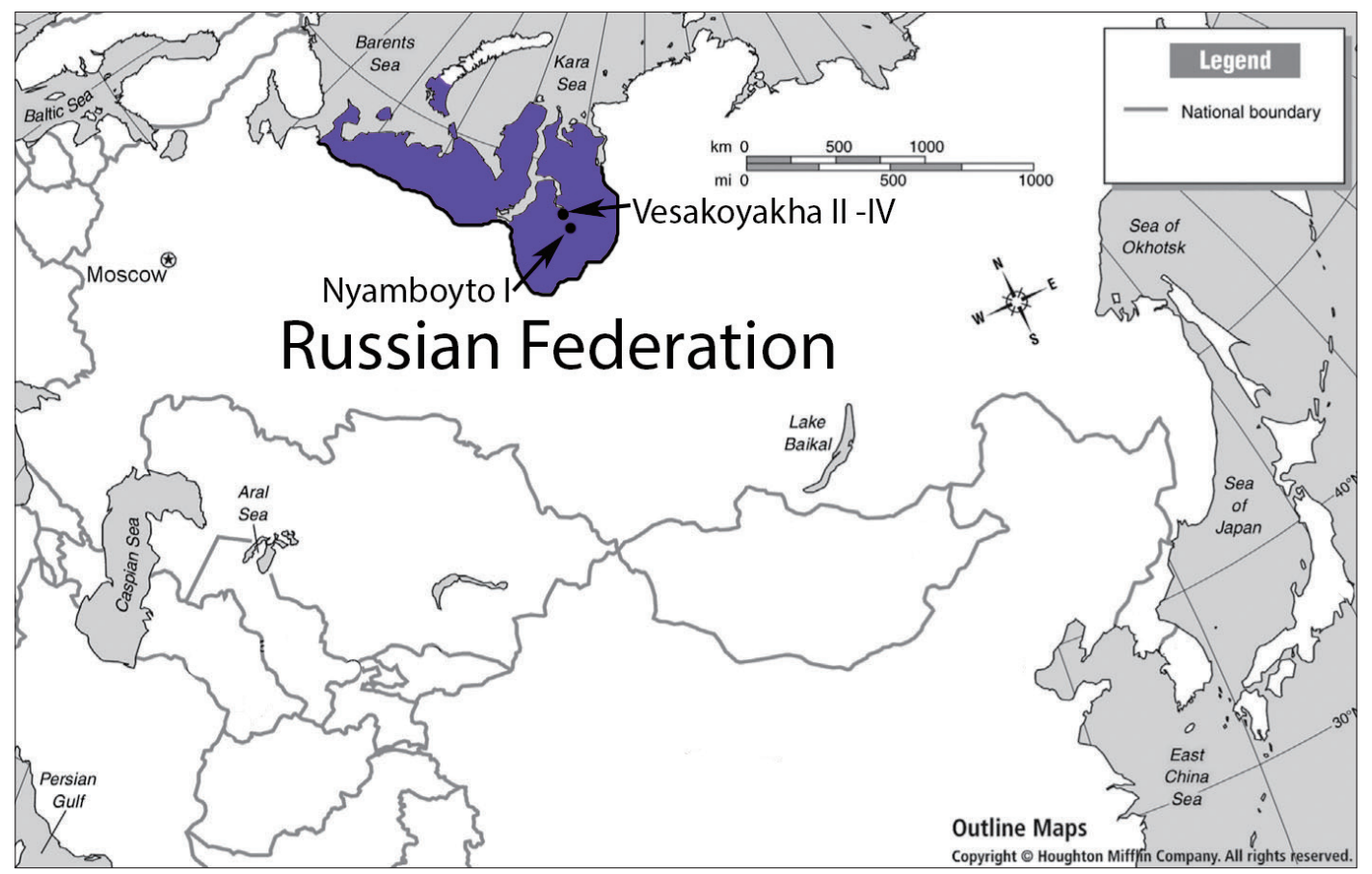

Fig. 1. Location of paleoparasitological investigations. Blue area of the residence of the Nenets.

with the Finno-Ugrian languages, falls within the Uralic language family belonging to the Ural-Altaic languages in Eurasia [5]. The subsistence of Tundra and Taz Nenets comes from reindeer farming and herding, as well as hunting and fishing [6].

This paper reports paleoparasitological results of soil samples collected from burial grounds near the Vesakoyakha River and Lake Nyamboyto. We infer food patterns and frequency and sources of helminthiasis, as well as reveal the presence of different types of intestinal parasites in the aforementioned populations.

\section{MATERIALS AND METHODS}

Three burial grounds of the Taz Nenets were investigated during the 2014 field season. Two samples were taken from 27 burials at the Vesakoyakha II burial ground. Six soil samples were collected from 12 and 8 burials at the Vesakoyakha VI and Vesakoyakha VII burial grounds, respectively. Thirteen soil samples were taken from 14 burials at the Nyamboyto I burial ground. All samples were collected from intact burials. Burials with skeletons in a distorted position were excluded from the study. Funeral garments and goods suggest that the burial grounds date from the 19th and early 20th centuries, respec- tively [7].

Soil samples were intentionally collected from the pelvic region. Each sample weighed about $100 \mathrm{~g}$, on average, and was marked and vacuum-packed in the field. We took soil control samples at the skull area from 1 burial in each burial ground.

We placed a dry $10 \mathrm{~g}$ sample into an $800 \mathrm{ml} \mathrm{L}$ Bunsen beaker and added 0.5\% trisodium phosphate solution $\left(\mathrm{Na}_{3} \mathrm{PO}_{4}\right)$ [8]. The Bunsen beakers were covered with filter paper, and the supernatant was elutriated 3 times over the course of a week, followed by sifting the residue through a $200 \mu \mathrm{m}$ sieve. Sample separation was performed in centrifugal tubes. The residue was gathered using a multiple centrifuge process for $7 \mathrm{~min}$ at 1,500 rounds per min. After that, we added glycerin until it covered the samples. We stirred the residue accurately and warmed up the tubes in a water-bath at $80^{\circ} \mathrm{C}$ for $10 \mathrm{~min}$. The hot tubes were centrifuged for $7 \mathrm{~min}$ at 1,500 rounds per min. Afterwards, glycerin and the remaining water were elutriated.

We prepared 20 microslides for each sample according to the recommended standard methods. Microscopic examination was conducted using AxioSkop 40 and MicMed 2 var. 2 microscopes under 80x and 400x magnifications. For measurements, AxioVision 4.6 and Scope Photo 3.0 software were used.

To determine the sex of the human remains, we observed 

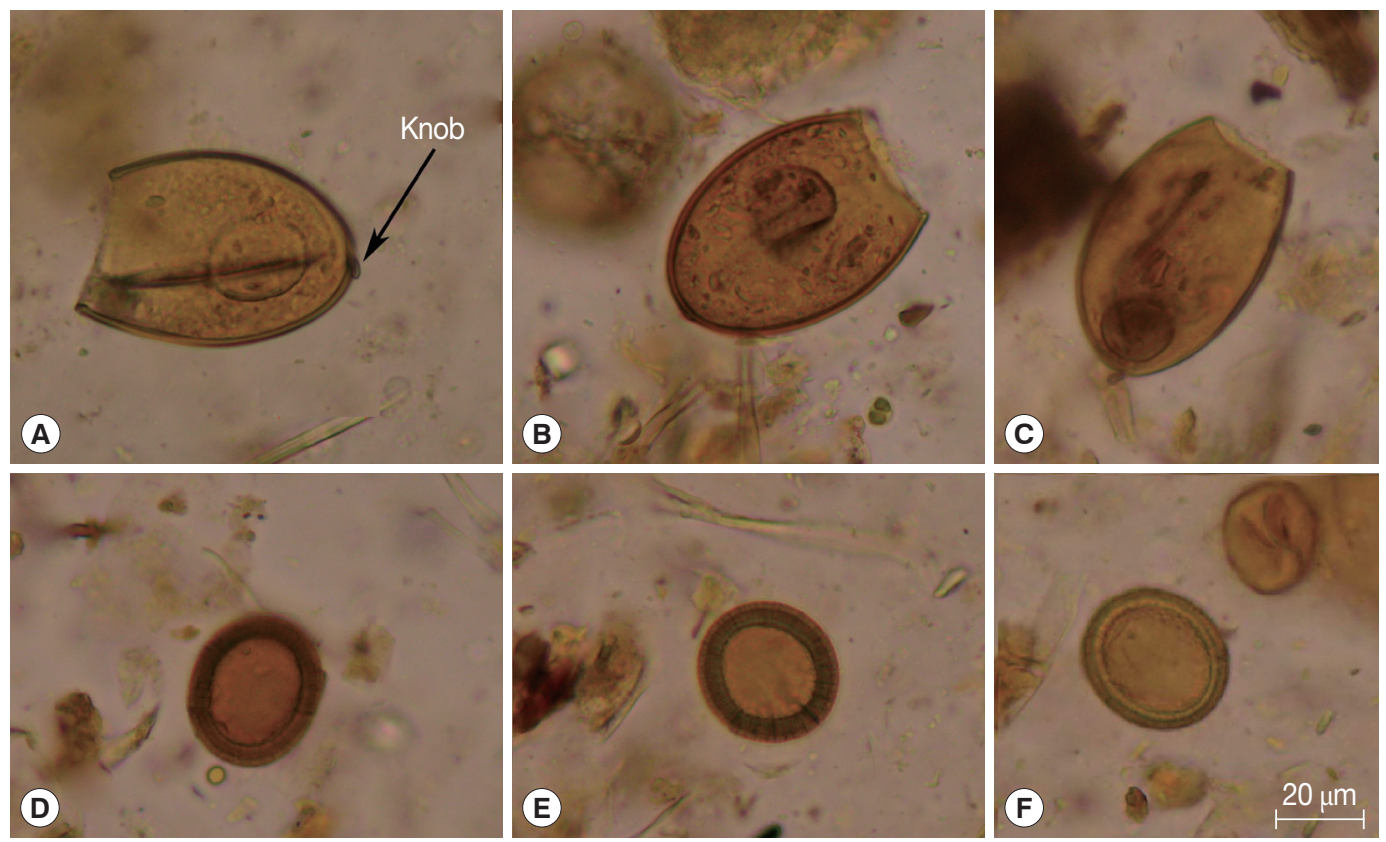

Fig. 2. Diphyllobothrium sp. eggs (A, B, and C) and Taenia sp. eggs (D, E, and F).

Table 1. Species composition of parasites and rate among age groups of Taz people

\begin{tabular}{|c|c|c|c|c|c|c|c|c|c|}
\hline Site & Burial no & Age & Sex & species & Site & Burial no & Age & Sex & species \\
\hline & & & & & VJA $\|^{d}$ & 4 & infans I & - & - \\
\hline $\mathrm{NBT}^{\mathrm{a}} \mathrm{I}$ & 1 & Maturus & $f^{b}$ & Diphyllobothrium sp. & VJA II & 6 & maturus & $f$ & - \\
\hline NBTI & $1^{\mathrm{a}}$ & infans I & - & Diphyllobothrium sp. & VJA III & 2 & maturus & $\mathrm{m}$ & Diphyllobothrium sp. \\
\hline NBT I & 2 & Adultus & $m^{c}$ & Diphyllobothrium sp. & VJA III & 3 & adultus & $\mathrm{m}$ & Taenia sp. \\
\hline NBT I & $2^{\mathrm{a}}$ & infans I & - & Diphyllobothrium sp. & VJA III & 5 & adultus & $\mathrm{m}$ & Taenia sp. \\
\hline NBT I & 3 & infans I & - & - & VJA III & 7 & maturus & $\mathrm{m}$ & - \\
\hline NBT I & $3^{\mathrm{a}}$ & infans I & - & Diphyllobothrium sp. & VJA III & 9 & maturus & $\mathrm{m}$ & - \\
\hline NBTI & 4 & Juvenis & - & Diphyllobothrium sp. & VJA III & 12 & adultus & $f$ & - \\
\hline NBT I & 5 & Maturus & $\mathrm{m}$ & Diphyllobothrium sp. & VJA IV & 2 & juvenis & - & - \\
\hline NBT I & 6 & infans I & - & - & VJAIV & 3 & maturus & $\mathrm{m}$ & Diphyllobothrium sp. \\
\hline NBT I & 7 & infans I & - & Diphyllobothrium sp. & VJA IV & 4 & adultus & $f$ & - \\
\hline NBT I & 8 & Senilis & $\mathrm{m}$ & Diphyllobothrium sp. & VJAIV & 6 & maturus & $f$ & - \\
\hline NBT I & 9 & Adultus & $\mathrm{m}$ & Diphyllobothrium sp. & VJA IV & 12 & adultus & $f$ & Diphyllobothrium sp. \\
\hline NBT I & 10 & infans I & - & Diphyllobothrium sp. & VJAIV & 14 & maturus & $\mathrm{m}$ & Diphyllobothrium sp. \\
\hline
\end{tabular}

aNyamboyto I burial ground.

bfemale.

cmale.

Vesakoyakha II - IV burial ground.

pelvic bones, skull, and mandible relying on standard methods [9]. The gender of young skeletons was not identified. The age of the skeletons was determined by cranial sutures, changes in symphysis pubis, transformation in auricular surface of pelvic bones, and tooth attrition. The age of young skeletons was defined by formation of dental structure [9].

On determining the sex and age, we divided individuals into the following groups: infants I (0-7 years), infants II (7-14 years), juveniles (14-20 years), adults (20-35 years), matures (35-55 years), and seniors ( $>55$ years). We used the chi-square test to test the null hypothesis [10].

\section{RESULTS}

Two species of intestinal parasite eggs were found in the soil samples. One of the species presented oval light brown eggs 
with a few having preserved operculum (Fig. 2). A knob was observed opposite to the operculum. The average egg diameter was $58.3 \times 43.0 \mu \mathrm{m}$ (550 eggs were measured). Relying on these morphological characters, we inferred that the eggs belong to the genus Diphyllobothrium [11]. Other eggs exhibited a light brown color, a spherical shape, and a thick radial striated eggshell. The egg diameter was $35.3 \times 30.7 \mu \mathrm{m}$ on average (150 eggs were measured). These morphological characters suggested that the eggs belong to the genus Taenia (Fig. 2) [11].

Out of 27 samples, 17 (63\%) showed helminth eggs. Diphyllobothrium sp. eggs were found in 11 (63\%) out of 13 samples from the Nyamboyto I burial ground, in 1 (16.7\%) out of 6 samples from the Vesakoyakha III burial ground, and in 3 (50\%) out of 6 samples from the Vesakoyakha IV burial ground. Two (33.3\%) out of 6 samples from the Vesakoyakha III burial ground contained Taenia sp. eggs.

Diphyllobothrium sp. eggs were found in $6(75 \%)$ out of 8 child burials and in 1 (50\%) of the 2 youth burials. In the adult group (adults, matures, and seniors), we detected helminth eggs in 11 (64.7\%) out of 17 burials. No significant differences in the helminth infection were found between the groups of children and adults $\left(\chi^{2}=0.084\right)$. Control samples were free from intestinal parasite eggs. The sex and age data of the human remains are given in Table 1.

\section{DISCUSSION}

Parasite eggs in soil strata from archeological sites are a valuable historical source of information about human food patterns, health status, and lifestyle. First, we will discuss on Diphyllobothrium sp. eggs found in the samples. Paleoparasitological studies suggested a high frequency of diphyllobothriasis in the past up to modern times [12]. Contemporary epidemiological evidence showed a high prevalence of diphyllobothriasis ( $87.5 \pm 4.1$ per 100,000 people) in Yamalo-Nenets Autonomous Okrug [13]. The infection rate among the population of the Taz region was 313.6 cases per 100,000 people [14]. The most pathogenic tapeworms for humans are Diphyllobothrium nihonkaiense, Diphyllobothrium dendriticum, Diphyllobothrium pacificum, and Diphyllobothrium latum. Of these, the latter (D. latum) infects humans more often than the others [15].

It is worth noting that Diphyllobothrium sp. eggs were found in 11 (84.6\%) out of 13 individuals (both children and adults) from the Nyamboyto I burial ground. In the early 20th century, doctors and ethnographers recorded fish tapeworm infec-

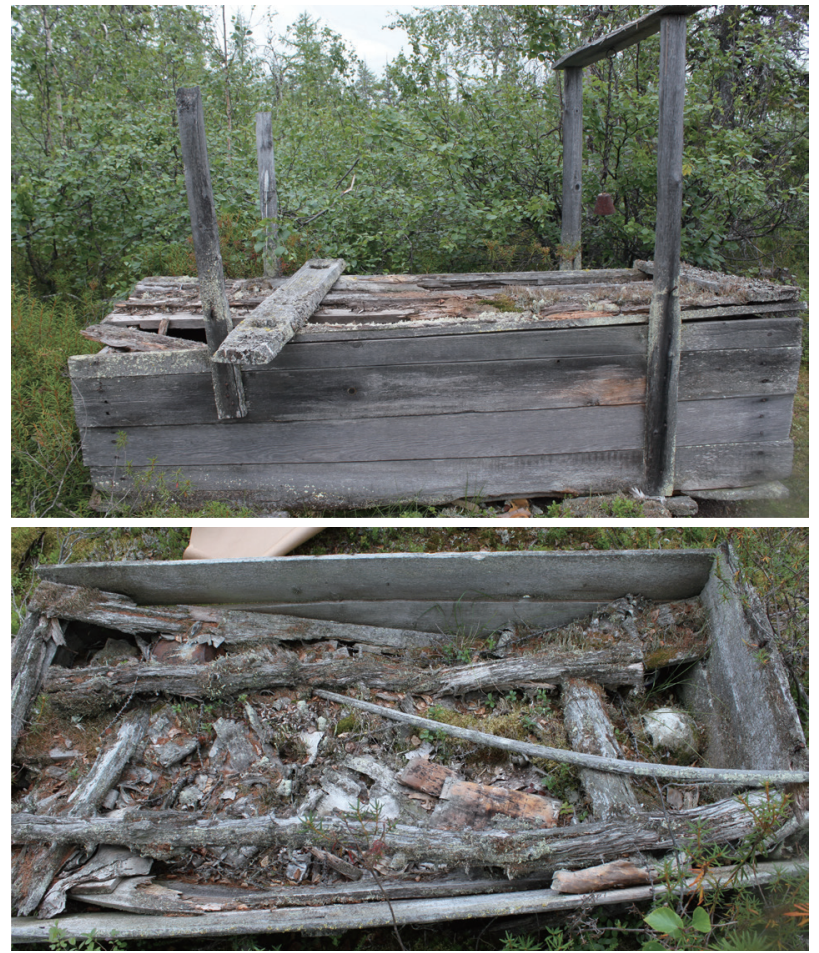

Fig. 3. On-ground burial boxes (Khalmer) of the Nenets.

tion among the indigenous people in the northern part of Western Siberia. However, available ethnographic studies for this territory are scarce. Some data suggested that the lower reaches of the Taz River were an ethnic contact zone between the Nenets and Enets [16] and, later, the Selkups, who settled there at the turn of the 20th century. Thus, the Nyamboyto I burial ground has burials of 2 types. Some are in-ground graves that belong to the Selkups, while the others are onground burial boxes (Khalmer) of the Nenets (Fig. 3) [17]. In the present study, we took samples from the burial boxes that feature only the Nenets. Ethnographic documents suggested causes of the highly prevalent diphyllobothriasis among the Nyamboyto I population. In the past, it is said that the Nyamboyto area was inhabited by the Nenets who had become poor and whose reindeer herd had died. The lake had an abundance of easy-to-catch fish. The Nenets and Selkups lived there together [17]. Ethnographic records about the Nenets from the lower reaches of the Taz River in the 19th to the early 20th centuries are unavailable. Therefore, we studied documents about other groups of Nenets and their neighbors. Subsistence activities were similar among the populations in the Tundra area in Western Siberia [18]. Ethnographic documents reveal certain sources of diphyllobothriasis among the Nenets 
from the northern part of Western Siberia. Specifically, all ethnographers state that the Nenets consumed large amounts of uncooked, frozen, and fresh-caught fish, as well as fish guts and liver oil [19]. Saltless dried fish was also largely consumed $[19,20]$. The Selkups from the upper Taz River followed a similar type of diet based on the consumption of raw fish. The population was highly infected with diphyllobothriasis $[21,22]$. Thus, the high prevalence of diphyllobothriasis among the Nenets who left the Nyamboyto I burial ground resulted from intensive fishing and consumption of uncooked fish as a major source caloric intake.

Soil samples from child burials at Nyamboyto I were largely infected with diphyllobothriasis. Eggs of Diphyllobothrium sp. were found in 5 (83\%) out of 6 child burials from 3 to 8 years old. Two burials of infants less than 3 years of age were free of diphyllobothriasis. This suggested that children became infected at 3 years of age and over when they began to consume uncooked fish. Different ethnographic records corroborate this suggestion. A historian G. F. Miller wrote that children were given raw fish at different ages. According to him, 2-year-old Samoyedic (also Nenets) infants were fed reindeer oil and chopped fish in order to get them used to raw food [23]. Ethnographer K. D. Nosilov pointed out that the Knanty from the Lower Ob, as well as the Nenets from Lake Nyamboyto, had no cattle or reindeer herds and gave children adult food. This ethnographer enumerates different fish species which were consumed, i.e., Stenodus leucichthys, Lota maculosa, Esox lucius, Perca fluviatilis, and Gymnocephalus [24]. Some species could have easily been contaminated with parasites.

Three burials at the Vesakhoyakha River were supposedly less infected with diphyllobothriasis. Unfortunately, a large part of the burial ground was damaged, and soil samples could not be taken. Therefore, we could not make a comparison between the Vesakoyakha and the studied Nyamboyto burial grounds. However, when we summed up all the diphyllobothriasis infection cases from the Vesakoyakha River and compared them with the infection records from the Nyamboyto burial ground, we arrived at a statistically significant difference $\left(\chi^{2}=4.356\right)$. These results mean that the Nenets from the Nyamboyto burial ground were highly infected with helminths. We may infer that the diet of the Nyamboyto Nenets was largely based on raw fish, while the Vesakhoyakha Nenets had a bigger variety in food which also included reindeer meat. The presence of Taenia sp. eggs in the soil samples from the Vesakoyakha VI burial ground corroborates this suggestion.
A human being may be infected with 3 genera of taeniid cestodes, i.e., Taenia saginata, Taenia solium, and Taenia asiatica. The eggs of these parasites are morphologically alike. The infection is caused by consumption of contaminated, undercooked, or uncooked beef or pork. In Yamalo-Nenets (YamaloNenetsky) autonomous okrug, the rate of Taenia infection is $0.31 \pm 0.2$ per 100,000 people, and the rate of beef tapeworm infection equals $9.28 \pm 1.3$ per 100,000 people [13]. However, in the 19th to early 20th centuries, taeniid infection rates were probably different. The source of beef or pork tapeworm infection, namely, cattle and pig bones, was found at the archeological site of Mangazeya, a Northwest Siberian trans-Ural trade colony and later city in the 17th century (1601-1672) and nearest settlement to the studied burial grounds. However, no bones of any domestic animals were found at excavation locations of indigenous people dating from the 16th to the early 20th centuries [25]. Moreover, no records indicated that the population in this territory bred cattle or pigs, or that they otherwise bought or procured beef and pork from other sources. In the locust years of the 19th to the early 20th centuries, the Russian Empire provided the Taz Nenets with bread only. Thus, we may infer that the consumption of raw beef and pork never took place and that these meats could not be sources of Taenia infection.

Of all the wild animals from the northern part of Western Siberia, only the moose and reindeer can be infected with beef tapeworm eggs. The moose population in Western Siberia was unstable for years, and, consequently, the northern boundaries of its range changed as well. The dramatic population drop was recorded in the 19th and early 20th centuries when the moose home range shifted significantly farther south than the location of the examined burial grounds [26]. Nowadays, moose are not found in the subarctic zone, entering the area only by chance [27]. Thus, it is very unlikely that moose could be a source of beef tapeworm infection.

Reindeer are widespread in the northern part of Western Siberia. Wild reindeer have never had a continuous range and are now found in large populations [28]. Reindeer hunting by the Nenets has been described by many ethnographers [29]. However, according to numerous ethnographic records, the Nenets often consumed raw reindeer meat [30]. Meat of dead or injured reindeer was frequently a part of food rations. However, consumption of raw reindeer meat cannot lead to beef tapeworm infection since T. saginata cysticerci develop only in reindeer cerebrum and cerebral meninges [31]. Nowadays, 
beef tapeworm episodes are recorded in Yamalo-Nenets (Yamalo-Nenetsky) autonomous okrug (YNAO) as a result of consuming raw reindeer cerebrum. This occurs among indigenous populations of northwestern Siberia during uncontrolled reindeer slaughter [32]. Ethnographic documents contain rare data about the consumption of uncooked reindeer cerebrum. According to historian Zuev (1771-1772), the Samoyedic people never boiled reindeer heads or ate raw cerebrum. This custom was also observed by O. Finsh and A. Brem. G. Miller writes in his works that they [the Nenets] seldom cooked food, preferring raw meat and fish, especially in winter when it was frozen. They never cooked reindeer heads, but ate them uncooked [33]. Thus, it can be inferred these people consumed the cerebrum and that such custom was the main cause of tapeworm infection.

This is the first parasitological analysis of helminthic diseases among the Taz Nenets. We discovered that the Taz Nenets were mostly infected with diphyllobothriasis. The Nenets from Lake Nyamboyto mainly consumed raw fish. The Nenets who left the Vesakoyakha burial ground had more variety in their food choices, including reindeer meat. Children were given raw fish from early childhood. The paleoparasitological results corroborated ethnographic records about the consumption of uncooked reindeer cerebrum which led to beef tapeworm infection.

In summary, this analysis contributes to a better understanding of the subsistence activities and food patterns of the Nenets from the lower Taz River Basin and broadens our knowledge about their health conditions.

\section{ACKNOWLEDGMENTS}

This research was made possible with the help of Alexander Ivanov, the head of Tazovskiy district (Yamalo-Nenets autonomous Okrug); Svetlana Eremina, the Head of the Department of Culture, Physical Culture and Sports, Tourism and Youth Policy; and Roman Berladin, the director of Tazovskiy Local History Museum. We would like to express our appreciation to Dr. Vladimir Adaev, who supported us all the time. The authors are grateful to Russian Science Foundation grant no. 1450-00036 for support.

\section{CONFLICT OF INTEREST}

We have no conflict of interest related to this work.

\section{REFERENCES}

1. Ferreira LF. Introduc, ão à paleoparasitologia. In Ferreira LF, Reinhard KJ, Araujo A eds, Fundamentos da Paleoparasitologia. Ed. Fiocruz, Rio de Janeiro, Brasil. 2011, pp 27-41.

2. Kvashnin YN. Ethnic and demographic processes in Taz Nenets at the beginning of the XXI century. Bull Archaeol Anthropol Ethnogr 2012; 3; 141-152.

3. Vasilev VI. The Nenets, Enets. The peoples of Siberia and northern Russia in the XIX century (ethnographic characteristics). Moscow, Russian Federation. 1994, pp 29-75.

4. Bagashev AN, Slepchenko SM. Materials of craniology of Taz Nenets. Materials of III All-Russian Conference "Man and the north: anthropology, archeology, ecology". Tyumen. Russian Federation. 2015, pp 6-10.

5. Ackerman F, Salminen T. Nenets. In Brown K ed, Encyclopedia of Language and Linguistics, Second ed. Vol. 1. Boston, USA. Elsevier. 2006, pp 577-579.

6. Golovnev AV. Historical typology of farming peoples of the North-Western Siberia. Novosibirsk, Russia. Publishing Novosibirsk University. 1993, pp 204.

7. Gavrilov IG, Safarov MY. Report on the research work on the execution of the identification and formulation of the state protection of objects of heritage of ethnic minorities of the North in the area Taz river YaNAO, Omsk, Russian Federation. 2011, pp 84 .

8. Callen EO, Cameron TWM. A prehistoric diet revealed in coprolites. New Scientist 1960; 7: 35-40.

9. Buikstra J, Ubelaker DH. Standards for data collection from human skeletal remains. In Proceedings of a Seminar at the Field Museum of Natural History Organized by Johnathan Haes. Fayetteville, Arkansas, USA. Archeological Survey Research Series No. 44. 1994, p 206.

10. Novikov DA, Novochadov VV. Statistical methods in biomedical experiments (typical cases). Volgograd, Russian Federation; Publishing VolGMU, 2005. p 84.

11. Ash LR, Orihel TC. Atlas of Human Parasitology. 4th ed. Chicago, Illinois, USA. American Society of Clinical Pathologists Press. 1997, pp 424.

12. Le Bailly M, Bouchet F. Diphyllobothrium in the past: review and new records. Int J Paleopathol 2013; 3: 182-187.

13. Dudarev AA, Dorofeyev VM, Dushkina EV, Alloyarov PR, Chupakhin VS, Sladkova YN, Kolesnikova TA, Fridman KB, Nilsson LM, Birgitta E. Food and water security issues in Russia III: foodand waterborne diseases in the Russian Arctic, Siberia and the Far East, 2000-2011. Int J Circumpolar Health 2013; Vol. 72: p 1-10.

14. State Reports [Rospotrebnadzor] On sanitary-epidemiological situation in Yamalo-Nenets AO. 2011.

15. Scholz T, García HH, Kuchta R, Wicht B. Update on the human broad tapeworm (genus Diphyllobothrium), including clinical relevance. Clin Microbiol 2009; 22: 146-160.

16. Kvashnin YN. Selkups the lower reaches of Taz river. Bull Archaeol Anthropol Ethnogr 2002; 4: 230-232. 
17. Kvashnin YN, Tkachev AA. Cult place on the lake Nyamboyto. Anthropol Forum 2014; 23: 185-194.

18. Khomich LV. Nenets. Moscow, Russian Federation. Science. $1966, \mathrm{p} 329$.

19. Zuev VF. Materials on the ethnography of the XVIII century (1771-1772). Moscow, USSA. Academy of Sciences. 1947, p 96.

20. Miller GF. The history of Siberia. T. 2. Moscow, Russian Federation. Publishing House "Eastern Literature" RAS. 2000, p 796.

21. Slepchenko SM, Ivanov SN. Paleoparasitological analysis of soil samples from the Kikki-Akki burial ground of the 17th-19th centuries in West Siberia, Russia. J Archaeol Sci (Reports) 2015; 2: 467-472.

22. Poshekhonova OE, Afonin AS, Kisagulov AV, Gimranov DO, Nekrasov AE, Yakimov SA, Yakimov AS, Bazhenov AI. Some elements of the funeral rite Northern Selkup according to paleoecological studies. Bull Archaeol Anthropol Ethnogr 2015; 4: 165-174.

23. Ehlert AH. North-Western Siberia in the shipping of labor and materials Georg Miller. Ekaterinburg. Russian Federation. 2006, p 416.

24. Nosilov KD. Northern stories. Sverdlovsk, USSA. 1937, p. 272.

25. Vizgalov GP, Kardash AV, Kosintsev PA, Lobanova TV. Historical
Ecology of the Population of the North of Western Siberia. Nefteyugansk. Russian Federation. AMB Yekaterinburg. 2013.

26. Geptner VG, Nasimovich AA, Bannikov AG. Mammals of the Soviet Union, T. 1. Moscow, USSA. Higher School. 1961, p 776.

27. Schwarts SS. Ways of adaptation of terrestrial vertebrates to the conditions of existence in the subarctic. Sverdlovsk, USSA. Academy of Sciences. 1963, p 131.

28. Bakhmutov VA, Azarov VI. Distribution, abundance and migration of wild reindeer in the north of the Tyumen region. Number and distribution of terrestrial vertebrates of Yamal and the surrounding area. Sverdlovsk, USSR. 1981, pp 19-26.

29. Simchenko YB. Culture reindeer hunters of Northern Eurasia. Moscow, USSA. Nauka. 1976, p 312.

30. Bakhrushin SV. Samoyed in the XVII century. Moscow-Leningrad, USSR. 1955, pp 5-7.

31. Istomin AV, Shushkova TS, Raegulov BM. Hygienic Problems of Ecology and Human Health in the Far North (Moscow). 2003.

32. On sanitary-epidemiological situation in the Yamalo-Nenets Autonomous District for the period 2006-2010 years, state report. Rospotrebnadzor. Salekhard, Russian Federation. 2011, p 222.

33. Finsch O, Bram A. Travel to Western Siberia. Moscow, Russian Empire. 1882, p 578. 
